Journal of Engineering Sciences, Assiut University, Vol. 40, No. 5, pp.1435-1453 - September 2012.

\title{
A COMPREHENSIVE APPROACH TO VERTICAL HANDOFF IN HETEROGENEOUS WIRELESS NETWORKS
}

\section{Prof. Gamal Abdel Fadeel Mohammed}

Electronic, Communication. and Computer Engineering. Dept., Faculty of Eng.,

Helwan, Cairo, Email : gam_hel@yahoo.com

(Received April 26, 2012 Accepted June 4, 2012)

A muti-criteria vertical handoff system sensitive to various mobile-terminals' mobility parameters including distance and velocity in a heterogeneous wireless network is analytically formulated and examined via simulations. It is targeted to estimate the essential handoff parameters including outage probability, residual capacity, signal to interference and noise threshold ratio and network access cost. In order to avoid the ping-pong effect in handoff, a signal evolution prediction system is formulated and its performance is examined. Moreover, the handoff scheme is triggered using an on line handoffinitiation-time estimation model. When initiated, the handoff procedures begin with network scoring procedures based on multi-attribute strategy which results in selection of potentially promising network parameters. Simulation results are shown to track well the analytical formulation.

\section{INTRODUCTION}

For seamless wireless communications, integration of wireless local area network (WLAN) and third generation (3G) cellular networks $(\mathrm{CN})$, should be developed, in order to achieve the targeted next generation wireless networks. These wireless access networks (WANs) are combined to provide a ubiquitous environment of wireless access for terminals equipped with multiple network interfaces, Fig. (1). When mobile terminal (MT) transfers from one network to another, the quality of service (QoS) offered by the network could be decreased under certain predefined level. This transfer mechanism is known as vertical handoff (VHO). A great deal of, previous, studies on VHO are based on received signal strength (RSS), in which handoff decisions are made by comparing the RSS with a preset threshold values [1-3]. Since RSS based VHO is not a QoS aware scheme, it cannot provide a better QoS to user to support multimedia services [4-6]. Moreover, since the achievable data rate of a MT is function of the received signal to interference and noise ratio (SINR). Therefore, a SINR based VHO is not expected to achieve maximum throughput and minimum dropping probabilities only, but also, it should lead to having a unified radio resource management for the heterogeneous wireless networks [7].

\section{LITERATURE SURVEY}

Vertical Handover [8], is a mechanism in which user maintains connection when switched from one WAN to another WAN technology (e.g., from WLAN to UMTS and vice versa , Fig.1). In references [9, 10], and [11], it is stated that VHO is different 
from the conventional horizontal handover wherein MT moves from one base station to another within the same network. In VHO, a session is seamlessly handed over to a new WAN in an interoperable region based on a criterion which evaluates the signal quality. The handover management procedures remain a widely studied issue in the case of heterogeneous network environment. Examples include the efforts provided by different working groups such as IEEE 802.21 [12], IETF MIP [13], or 3GPP standards [14]. In particular, IEEE 802.21 supports a mobile-controlled handover (MCHO) scheme with MIP as its mobility management protocol. However, details of network selection entity and the specifications of the handover policies that control handovers are outside the scope of the 802.21.

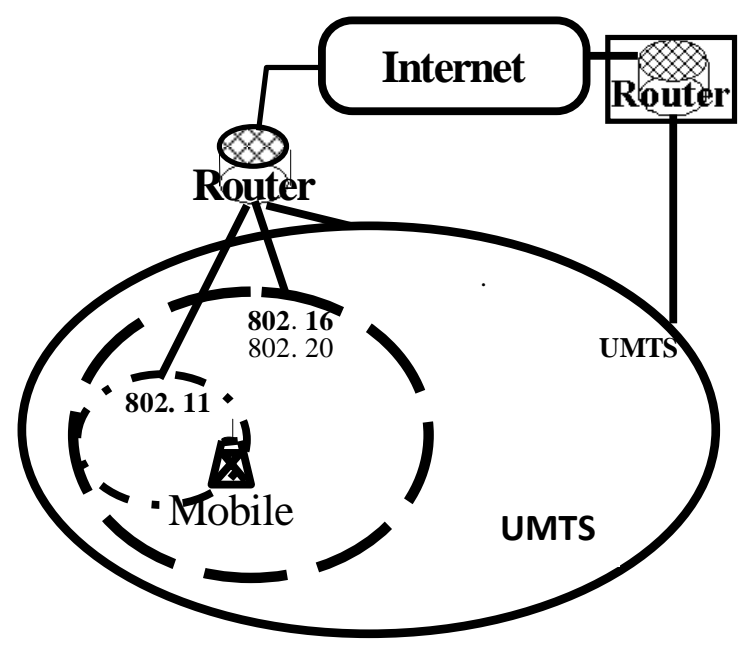

Fig. (1), Heterogeneous Network Overlay

The objective of a VHO strategy is to guarantee QoS for a variety of applications. In general, the strategy can perform a complex decision criterion that combines large number of (QoS) metrics. The first VHO decision scheme, that considered multiple criteria policies, was proposed by [15]. It introduced a cost function to select the best available WAN based on three policy parameters: bandwidth, power consumption, and cost. Reference [16] proposed also a multiservice VHO decision algorithm based on cost function. However, for more efficiency and taking into account more criteria, context-aware decision solution has inspired the authors in [17, 18], and [19]. In reference [18], the authors designed a cross-layer architecture providing contextawareness, smart handover, and mobility control in a W-WAN to WLAN environment. They proposed a VHO decision, with a cost function-based solution, taking into account network characteristics and higher level parameters from transport and application layers. References [17, 19], and [20], are based on a multiple criteria decision-making algorithm, analytic hierarchy process (AHP). A more advanced multiple criteria decision algorithms are presented in [21], and [22], wherein the authors applied the concept of fuzzy logic (FL). They employ decision criteria such as user preferences, link quality, cost, or QoS. Upon literature review, mobility prediction schemes in handoff procedure were found to be very critical in the handoff performance. The handoff procedure is typically based on the RSS from the base 
station. There exist several models, schemes and algorithms for handoff procedure which is based on the RSS values as proposed in [23, 24], and [25]. These published methods are regularly based on hysteresis and threshold methods.

In this paper, a comprehensive methodology for mobility-prediction based VHO scheme is proposed. In this respect, the proposed VHO algorithm considers the received SINR as its handoff criterion. Moreover, the handover process is split into number of stages: handover initiation decision which involves the decision to which point of attachment to execute the handover and its timing. Next, radio link transfer which is the task of forming links to the new point of attachment is based on the estimation of a significant QoS metrics that is seen to satisfy the basic requirements of a variety of applications.

This paper is organized as follows; section 3 outlines the SINR based VHO strategy. Section 4 presents a signal prediction model to predict future SINR evolution and enhances the handoff process. In section 5 a set of QoS parameters necessary for handover is analytically formulated. Section 6 presents a network selection scheme with examples to validate its performance in Wi Fi, Wi MAX and UMTS networks. The research work carried out in this paper is concluded in section 7 .

\section{SINR-BASD VERTICAL HANDOFF STRATEGY}

In order to provide guaranteed QoS, the VHO algorithm must be QoS aware. Traditional received signal strength (RSS) based vertical handoff algorithm cannot achieve such QoS awareness [26, 27], and [28]. Therefore, we have considered the SINR as handoff criteria similar to that proposed in [29]. A SINR based vertical handoff technique, according to Shannon's capacity formula, states that, the maximum achievable data rate $\mathbf{R}_{A P}$ from WLAN (Access point, AP) and, $\mathbf{R}_{\mathrm{BS}}$ from WCDMA (Base station, BS) can be represented by the receiving SINR: $\gamma_{A P}$ and $\gamma_{B S .}$

$$
\begin{aligned}
& R_{A P}=W_{A P} \log _{2}\left(1+\frac{y_{A P}}{\Gamma_{A F}}\right), \\
& R_{B S}=W_{B S} \log _{2}\left(1+\frac{\gamma_{E S}}{\Gamma_{B S}}\right)
\end{aligned}
$$

where $W_{A P}=22 \mathrm{MHz}[30]$, and $W_{B S}=5 \mathrm{MHz}$ [31] are carrier bandwidth of WLAN, WCDMA, $\Gamma_{A P}=3 \mathrm{~dB}$ [32] and $\Gamma_{B S}=12 \mathrm{~dB}$ [30] are channel coding loss factors. Since the data rates of both networks are different, therefore, to compare the SINR of the two networks, the SINR of the source network must be converted to the SINR of the destination. Thus, assuming the data rates $R_{A P}$, and $R_{B S}$ to be equal, the relationship between the SINR of WCDMA and Wi-Fi can be obtained as given below:

$$
\gamma_{B S}=\Gamma_{\mathrm{BS}}\left(\left(1+\frac{\gamma_{A P}}{\Gamma_{A P}}\right)^{\frac{W_{A P}}{W_{B S}}}-1\right)
$$

The relationship in (3) makes the SINR based VHO an applicable method, in which the receiving SINR from WCDMA is being converted to the equivalent, $\gamma_{\text {AP }}$ required 
to achieve the same data rate in WLAN, and compared with the actual receiving SINR from WLAN. Handoff is triggered when the user receives higher equivalent SINR from another access network. This gives the vertical handoff mechanism the ability to make handoff decision with multimedia QoS consideration, such as the user maximum downlink throughput and minimum probability of HO dropping.

\section{SINR PREDICTION SCHEME FOR HETEROGENEOUS WIRELESS NETWORKS}

As previously mentioned, the achievable data rate of a MT is a function of the received SINR, which is proportional to the distance between access point (AP) (or (BS)) to the mobile user and to the noise and current interference levels. A significant characteristic of the SINR is its high fluctuations caused by user speed as well as the effect of fading, shadowing attenuations. Such variations could cause some unnecessary handoffs especially at cell boundaries, a phenomenon referred to as pingpong effect. In the following we present a SINR evolution-prediction model to be adopted in the rest of this paper. The main task of the prediction system is to extract realistic governing laws of the SINR using available measurements. This process is known as the generation of the grey sequence [33], [35] and [36]. In grey models, the future values of a time series is predicted based only on a set of the most recent measurements depending on the window size of the predictor. Consider the following time sequence :

$$
\mathrm{X}^{0}=\mathrm{X}^{0}(1), \mathrm{X}^{0}(2), \ldots, \mathrm{X}^{0}(\mathrm{n}), \quad \mathrm{n} \geq 4
$$

where $\mathrm{X}^{0}$, is a non-negative sequence and $\mathrm{n}$ is the sample size of the received data. To obtain the predicted value of the data at time $(\mathrm{k}+1)$, the following formula is used :

$$
\mathrm{X}_{\mathrm{p}}^{0}(\mathrm{k}+1)=\left(\mathrm{X}^{0}(1)-\frac{\mathrm{b}}{\mathrm{a}}\right) \mathrm{e}^{-\mathrm{ak}}\left(1-\mathrm{e}^{\mathrm{a}}\right)
$$

(see Appendix for details and parameter definitions), and the predicted value of data at a future time instant $(\mathrm{k}+\mathrm{H})$ is as follows :

$$
\mathrm{X}_{\mathrm{p}}^{0}(\mathrm{k}+\mathrm{H})=\left(\mathrm{X}^{0}(1)-\frac{b}{\mathrm{a}}\right) \mathrm{e}^{-\mathrm{a}(\mathrm{k}+\mathrm{H}-1)}\left(1-\mathrm{e}^{\mathrm{a}}\right)
$$

To demonstrate the efficiency of the proposed SINR prediction model, the actual value $\mathrm{X}^{0}$ and the forecasted value $\mathrm{X}_{\mathrm{p}}^{0}(\mathrm{k}+\mathrm{H})$ are compared in the following subsection.

\subsection{Preliminary Simulations: Parameters and Modeling}

The simulation study is underpinned by a series of assumptions that we shall describe. A WLAN simulation model is developed as shown in Fig. (1). In this model, MTs move from one cell to another with varying speeds. The received signals from the base stations are affected by two major factors: path loss and shadow fading.

$\mathrm{L}_{\mathrm{dB}}=\mathrm{PL}+10 \mathrm{q} \log (\mathrm{d})+\mathrm{S}$ 
where PL is constant power loss, $\mathrm{q}$ is path loss exponent with values between 2 to 4 , $\mathrm{d}$ represents the distance between the MT and WLAN's AP and S, represents shadow fading which is modeled as Gaussian with mean $\mu=0$ and standard deviation $\sigma$ with values between 6-12 $\mathrm{dB}$ depending on the environment [36].

\subsection{Simulation Results}

The SINR received from AP is calculated at different mobile speeds and is shown in Fig. (2). In the simulation model, mobile speeds are controlled using two parameters: $\Delta \mathrm{x}$ and $\Delta \mathrm{t}$ representing, respectively, the difference of distances, $\Delta \mathrm{x}$, travelled during fixed time intervals $\Delta t$. Figure (2), shows the relationship between SINR and the "relative" (simulation) mobile speeds across the WLAN coverage area for speeds ranging from $1 \mathrm{~km} / \mathrm{h}$ to $100 \mathrm{~km} / \mathrm{h}$.

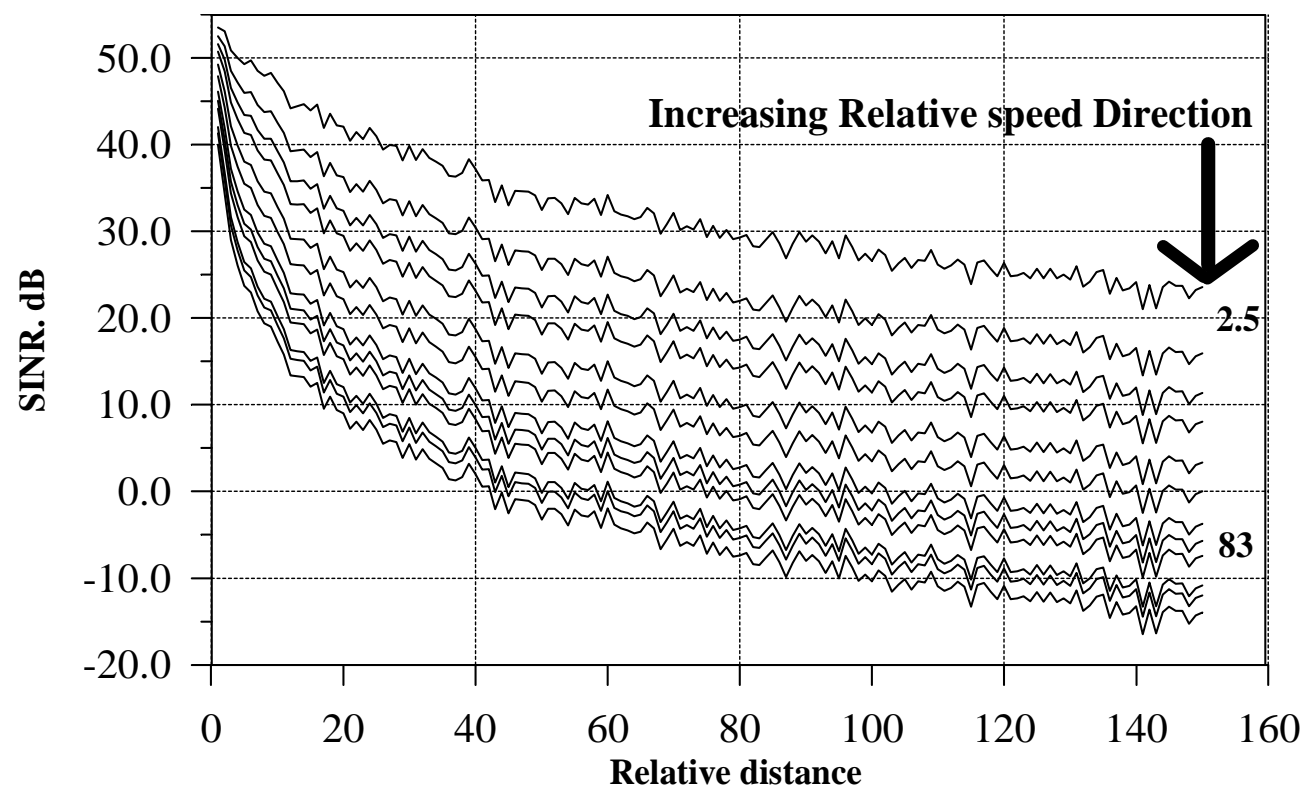

Fig.(2), Effect of Mobile (relative) Speed on SINR.

Of importance here to mention that, in real life systems, a "calibration" based formula should, initially, be defined via a set of "practical" experiments to quantify the relationship between the SINR measurements and the actual mobile speeds in real wireless networks.

Basically, the mobile node measures SINR periodically every $\Delta \mathrm{t}$ - seconds, the evolution of SINR can, then, be translated into the evolution of the "relative" distance between mobile nodes and their base stations as well as their speeds.

As can be seen (Fig. (2)), SINR is significantly sensitive to mobility of the users in terms of their distances and speeds. Moreover, an evident characteristic of the SINR is its significant fluctuations caused by fading and shadowing as well as by the speeds of MTs.

Figure (3), compares the actual values of received SINR and the corresponding prediction values. The simulation results show that the grey model tracks well the 
evolution of the measured SINR data. A desirable feature of the prediction results is that it reveals the exact trends of the current SINR measurements.

\section{SINR-BASED HANDOFF PARAMETERS FOR HETEROGENEOUS WIRELESS NETWORKS}

This section proposes different parameters that are seen to be necessary and sufficient for mobility management in VHO systems. The objective is to provide the proper information required to offer a seamless handover services for the end users. First, we show how to decide and when to perform VHO. Second, the results of the proposed VHO protocol are presented. The two phases are implemented via simulation models including 802.11, 802.16 and UMTS technologies developed for this purpose.

\subsection{Vertical Handoff Triggering-Time Estimation Model}

In a heterogeneous network environment, the ping-pong effect occurs if factors for the VHO decision are changing rapidly (see Fig. (2)), and MT performs handover as soon as it detects the better AP/BS [10]. A dwell timer scheme has been used to avoid such ping-pong effect [37], [38]. It starts to work when the vertical handover condition is first satisfied. If the VHO condition persists during the dwell time, the MT performs vertical handover to the target BS/AP after the dwell timer is expired. Otherwise, the MT resets the dwell timer [39]. Consequently, the MT does not execute premature vertical handover until the target BS/AP becomes stable. However, ping-pong effect can occur if the speed of the MT is relatively high or its moving direction is irregular.

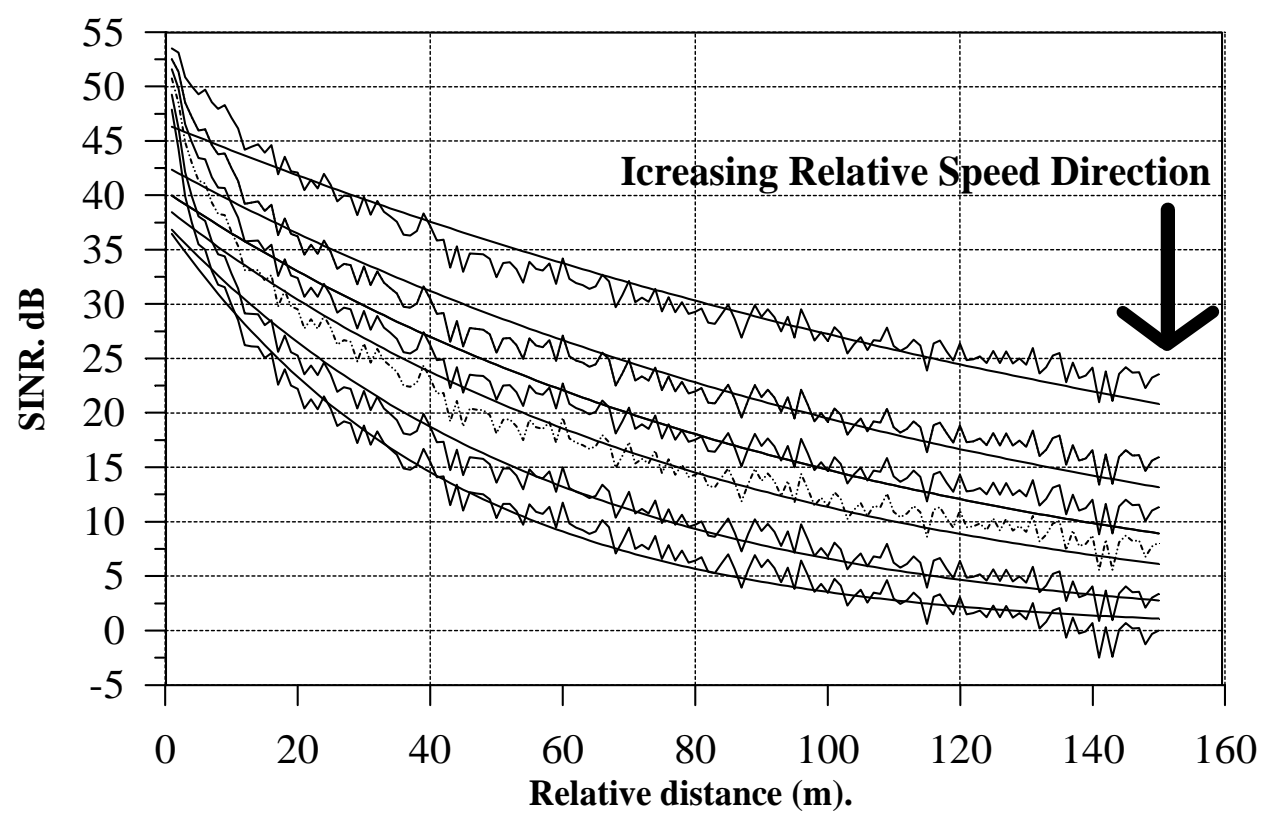

Fig.(3), SINR Prediction 
In this paper, we propose a disconnection (breaking)-time estimation scheme wherein an estimate for the mobile's speed, $V^{v}=\lim _{\Delta t \rightarrow 0} \frac{\Delta x}{\Delta t}$, is obtained, with $\Delta x$ and $\Delta \mathrm{t}$ designate the differences of distances travelled and time intervals respectively. Then an estimate of the disconnection time is found. Basically, the MT measures SINR periodically every $\mathrm{n}$ second(s). With the prediction model (section 4 ) integrated in the present (VHO timing) model, the SINR variations are smoothed out. Then, the evolution of SINR is translated into the evolution of the relative distance between MT and the base station. Hence, the relative speed and disconnection time are estimated as follows. Since

$\operatorname{SINR}(\mathrm{dB})=\mathrm{A}-\mathrm{B} * \log 10($ distance $)$

with the coefficients A and B vary according to the frequency of emitting signal then,

$\mathrm{V}=\left(10^{\frac{\mathrm{K}-\mathrm{SINR}(\mathrm{i})}{\mathrm{B}}}-10^{\frac{\mathrm{K}-\mathrm{SINR}, \mathrm{i}-\mathrm{-1})}{\mathrm{B}}}\right) / \mathrm{n}$

where, $\operatorname{SNR}(\mathrm{i})$ is the current measurement and SNR(i-1) is the previous one. Clearly, $\mathrm{V}$ $>0$, means the MT is moving away from the AP, $\mathrm{V}<0$ indicates that the MT is moving towards the AP. Note that, this equivalent speed does not represent the real speed of the mobile node. Once again, a calibration formula should be used to match the measurements with real life situations. Now, from Shannon's capacity formula, we can define SINR threshold, $Y_{\text {thr }}$, as the critical threshold under which wireless communications cannot be supported anymore,

$\gamma_{\text {thr }}=\operatorname{SINR}_{\text {thr }}=\Gamma_{A P}\left(2^{\frac{R}{W}}-1\right)$,

where $\mathrm{R}, \mathrm{W}$ are, respectively, the user data rate and the channel bandwidth. Then, we can estimate the relative time $\left(\mathrm{T}_{\text {Break }}\right.$ ) when the mobile node will get disconnected according to its current relative position and positive speed estimate,

$\mathrm{T}_{\text {Break }}=\frac{10^{\frac{\mathrm{K}-\mathrm{v}_{\mathrm{thr}}}{\mathrm{B}}}-10^{\frac{\mathrm{K}-\text { suNR(j) }}{\mathrm{B}}}}{\mathrm{T}}$

From Equs. (9) and (11), we have:

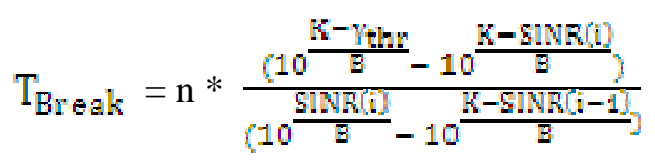

Equation (12) allows estimating the future signal variation and, hence, the MT's mobility evolution. Then, it can deduce as when the MT is about to migrate out of the current wireless coverage. Based on the prediction, the MT is able to decide on triggering the $\mathrm{VHO}$ procedures but at the right time.

Figure (4), shows the simulation results for the disconnection-time estimation technique (Equ.12). As can be seen, due to estimate fluctuations, it is relatively difficult to decide on the exact time to trigger the handoff procedure. This is where the prediction scheme comes into play in order to define the exact VHO timing. Figure (5), 
depicts the results of using the prediction scheme. As can be seen, knowing the "crossover time", the MT can decide on 'triggering' (initializing) the handoff procedure so that it avoids unnecessary handoffs caused by the significant uncertainties seen in Fig.(4).

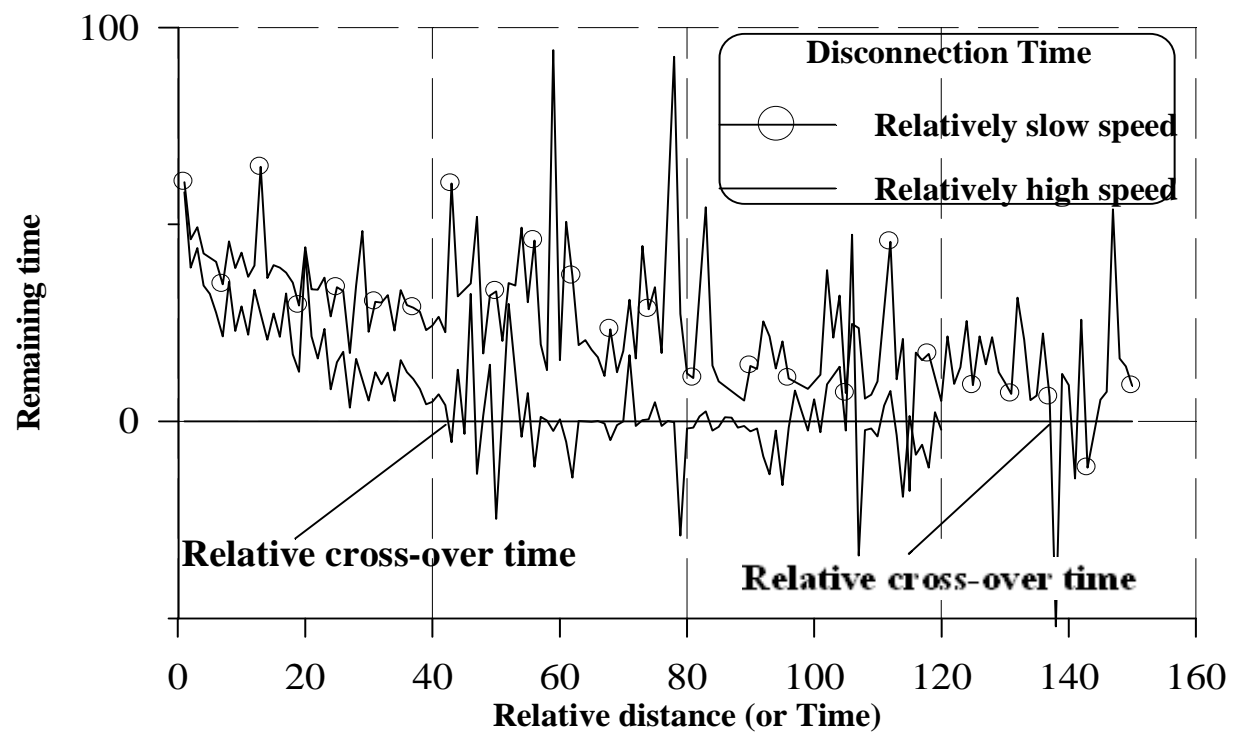

Fig.(4), Effect of mobility speed on breaking time.

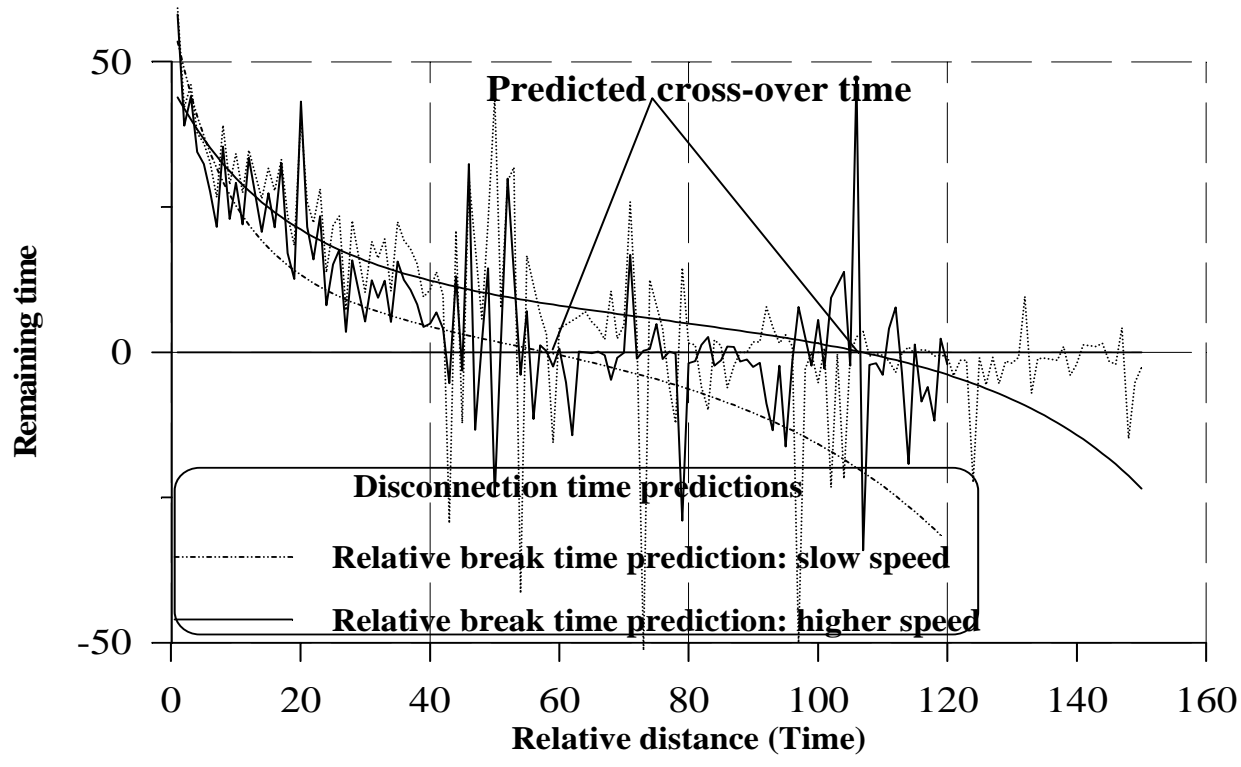

Fig.(5), Break time prediction

\subsection{Outage Probability Estimation Model}

In wireless environment, network throughput should be kept above a target value and, therefore, packet delay can also be kept below a target value for a certain application class. This has been, traditionally, characterized by the SINR values. 
However, guaranteeing SINRs of all applications at all time instances may result in low network utilization especially for bursty traffic. Therefore, in this paper, beside the SINR, we use another QoS metric, namely, the SINR-outage probability. That is, instead of guaranteeing the SINR at all the time, we can guarantee that the SINR outage probability is below some target value. In the following we derive the SINR outage probability.

In general, the propagation attenuation for a user at a distance $r$ from the base station is modeled [40] as:

$$
\alpha(r, \xi)=r^{\mu} 10^{\xi / 10} \text {, }
$$

where $\mu$ is the power of the distance $r$, and $\xi$ is the $\mathrm{dB}$ attenuation due to log-normal shadowing with zero mean and standard deviation $\sigma$. Suppose that we impose the requirement that the link achieves at least the performance of un-shadowed propagation for all but a fraction, $P_{\text {out }}$, of the time which is denoted the outage probability. This means that the desired performance will be achieved whenever the shadowing attenuation $\xi \leq \gamma$ where $\gamma$ here designates the SINR. Hence, the outage probability, or the fraction of time wherein the performance is not achieved is,

$$
P_{\text {out }}=\operatorname{Pr}(\xi \geqslant \gamma)=\frac{1}{\sqrt{2 \pi}} \int_{\gamma}^{\infty} \mathrm{e}^{-\frac{\xi}{2 \sigma^{2}}} \mathrm{~d} \xi=\mathrm{Q}\left(\frac{\gamma}{\sigma}\right)
$$

where $\mathrm{Q}($.$) designates the complement error function. Figure (6), shows the simulation$ results of the outage probability at different locations and speeds within the coverage area of 802.11. The prediction mechanism (section 4) is, again, integrated within the outage probability estimation model in order to smooth out the probability results. As can be seen, the outage probability estimate shows a desirable sensitivity to mobile's speed as well as its relative location in the coverage area of the AP. This reveals the fact that our estimation scheme will play an important role in making efficient handoff decision as will be seen later.

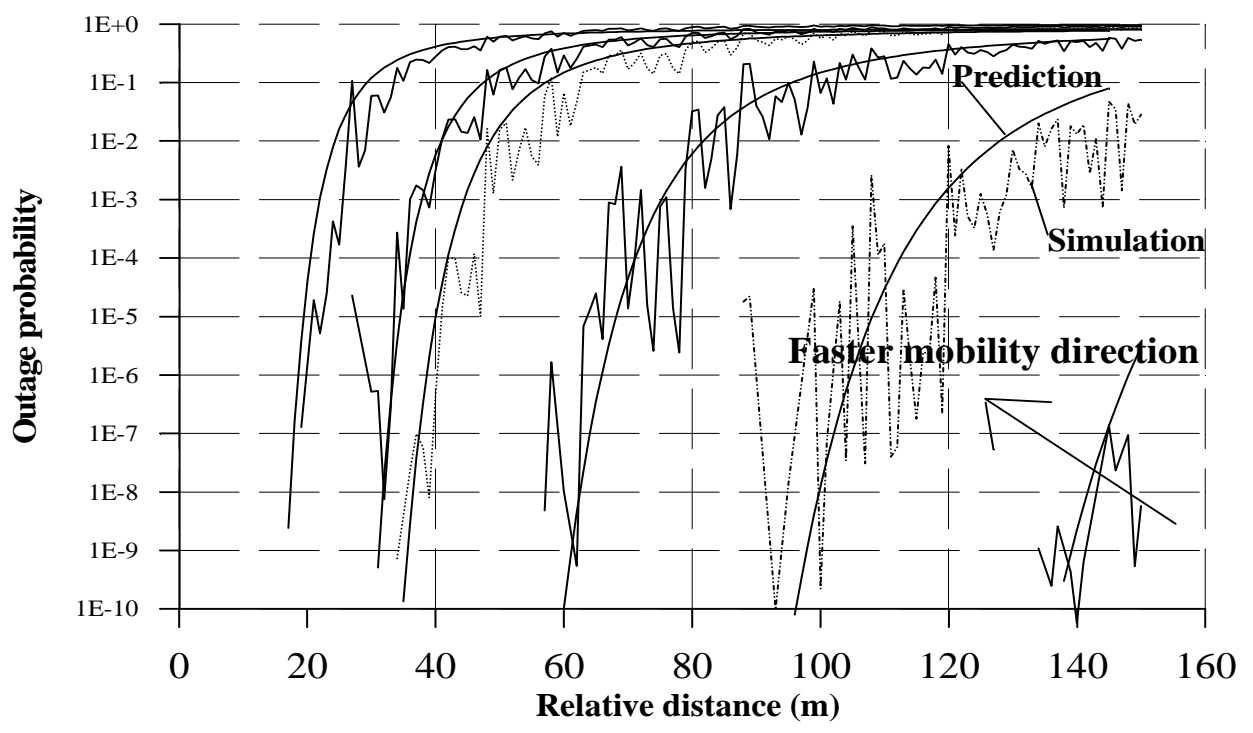

Fig.(6), Outage probability prediction. 


\subsection{Residual Capacity Estimation Model}

In VHO, users seek for maximum available bandwidth from the integrated heterogeneous networks especially for multimedia services. In this paper, MT keeps measuring received SINR for Wi Fi, Wi MAX and UMTS, conducting the $\gamma_{\mathrm{AP}}, \gamma_{\mathrm{BS}}$ and $Y_{\text {MAX }}$ conversions (section 3). The handoff strategy (next section), allocates users with low bandwidth requirements to networks optimized for a particular data rate and service provisioning and, hence, leaves high speed connections free for users requiring high QoSs. In [41], the concept of residual capacity was introduced as the additional number of calls a base station can accept such that the system wide outage probability will be guaranteed to remain below a certain level. The residual capacity is dynamically updated at each cell according to the SINR measurements. The residual capacity is defined as follows,

$$
\mathrm{C}_{\mathrm{rgd}}=\left[\frac{1}{\operatorname{sinR}_{\mathrm{th} r}}-\frac{1}{\operatorname{SINR}_{\mathrm{k}}}\right]
$$

where $\mathrm{SINR}_{\mathrm{thr}}$ and $\mathrm{SINR}_{\mathrm{k}}$ are the minimum SINR required to support the service rate and the actual SINR received, respectively. It is envisaged that a SINR- based $\mathrm{C}_{\mathrm{rsd}}$ will play an important role in the handoff strategy proposed in this paper.

Figure(7), depicts the simulation/prediction results for the residual capacity estimation scheme. Here, the estimator and predictor obtains the $\mathrm{C}_{\mathrm{rsd}}$ estimates of all neighboring networks and decide as to which network it should hands off. As can be seen, the residual capacity prediction follows well the simulation results. In the following section we present our handoff strategy.

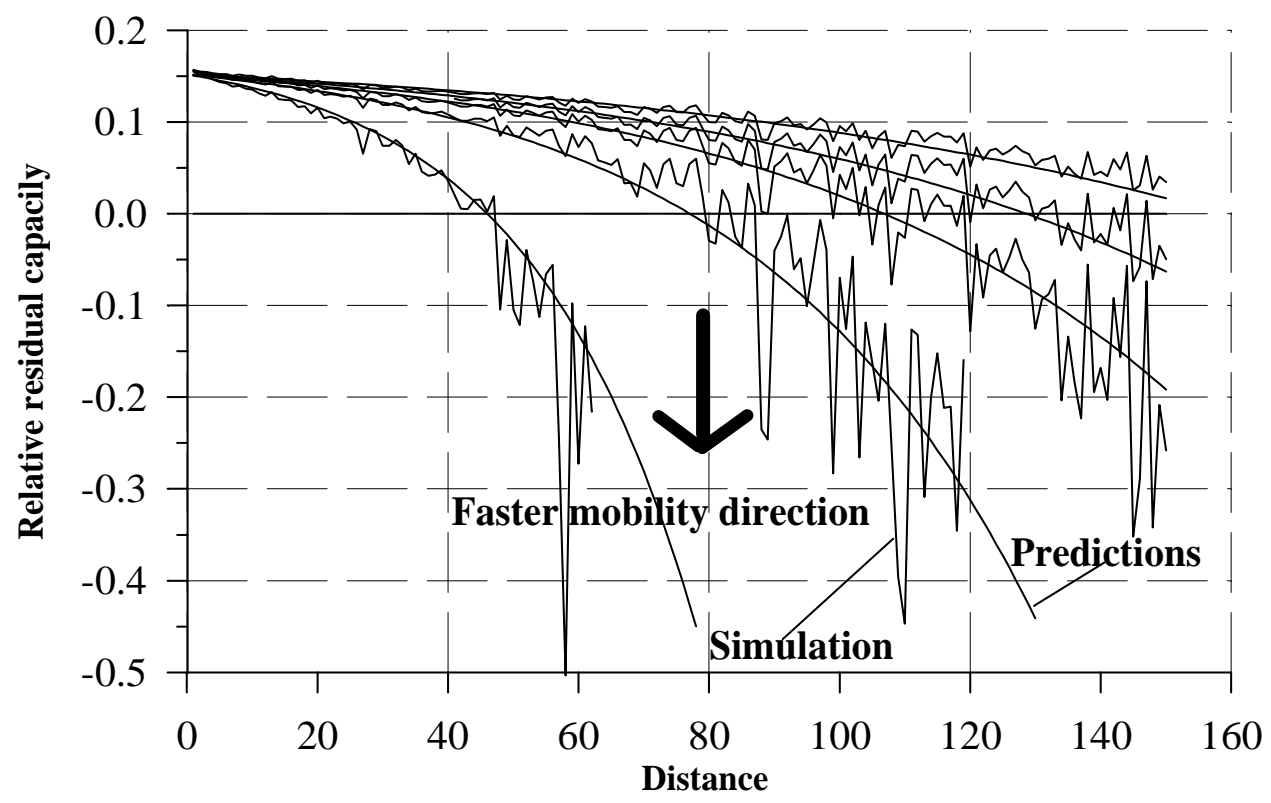

Fig.(7), Residual capacity prediction 


\section{VERTICAL HANDOVER STRATEGY}

This section proposes a mobility management strategy for integrated heterogeneous wireless networks. The objective is to guarantee QoS for a variety of applications with different QoS requirements. In general, the strategy can perform a complex decision criterion that combines large number of (QoS) parameters including (in our case), outage probabilities, residual capacities, SINR thresholds in addition to network access costs if necessary. Selection of potential network(s) will be based on a network scoring scheme that will be presented later. But, for now, the handoff process is seen to be composed of three phases: network discovery, handoff-triggering/initiation decision and handoff execution. In the following, the network discovery and handoff initiation phases are presented.

\subsection{Handoff initiation/triggering decision}

The simplest way for a multiple interfaces MT to discover reachable wireless networks is to keep all air-interfaces $\mathrm{ON}$ at all times. However, keeping an air interface active all the time consumes battery power and bandwidth even when the MT is not sending or receiving any packets. The handoff decision refers to the process of deciding on the right moment when to perform the handoff. It is, thus, critical to avoid keeping idle air interfaces perpetually ON. Moreover, in order to avoid the ping-pong effect, MTs must observe if the neighboring network(s) is consistently better than the current one before initiating handoff.

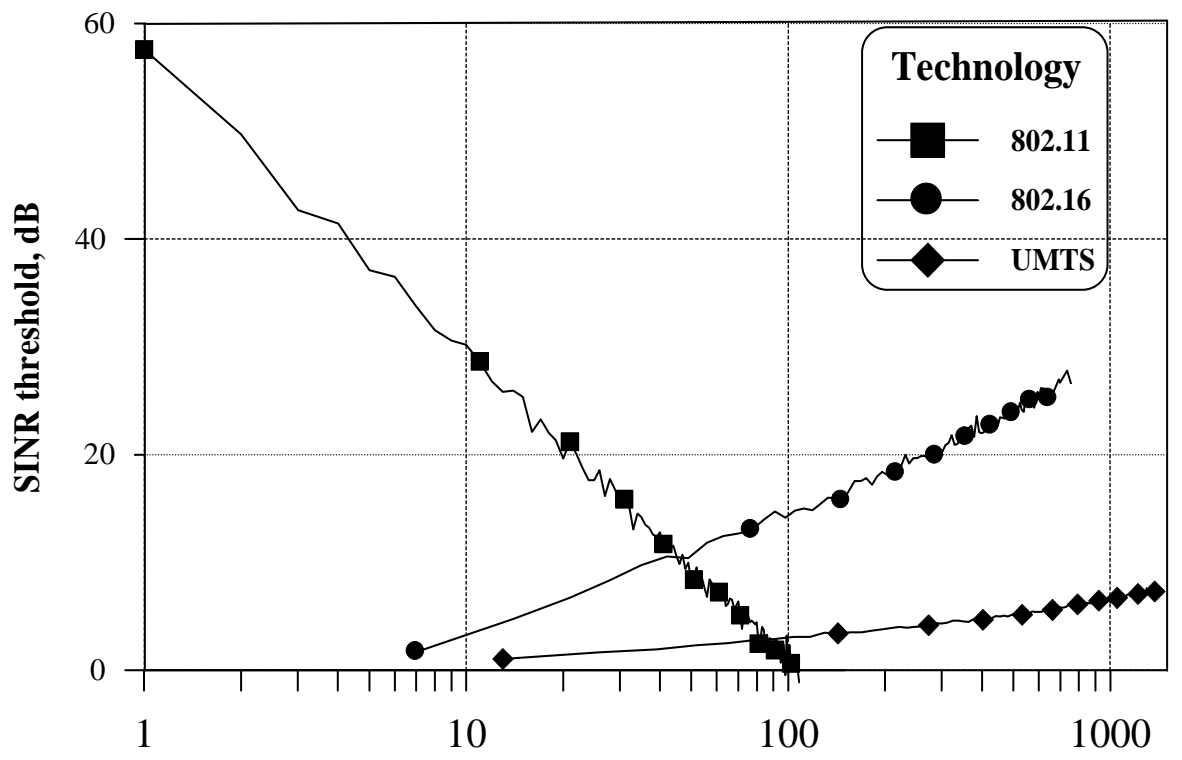

Relative distance (meter)

Fig.(8), SINR monitoring: threshold at handoff time.

Primarily, the SINR is monitored and used in future evolution prediction for the attached AP and neighboring networks. An example is shown in Figures (8) and (9). Note that in Fig. (8), the SINR monitored, SINR Monj $_{\text {in }}$ represents the difference 
between the observed SINR and that required to satisfy the user's application requirements (equation (16) below), assuming that the MT is currently covered under the 802.11 , and is migrating to either 802.16 or UMTS. The same scenario applies for the outage probability depicted in Fig. (9).

$$
\operatorname{SINR}_{\text {Moni }}=\left(\text { SINR }_{\text {Appl- }} \text { SINR }_{\text {thr }}\right)
$$

Next, the handover decision function comes into play (see section 5.1), where it helps estimating the "cross-over" moment (see Fig.(5)) in order to trigger VHO procedures by starting the network scoring scheme. Hence, selection of the most promising network is carried out. In the following, the network scoring scheme is presented.

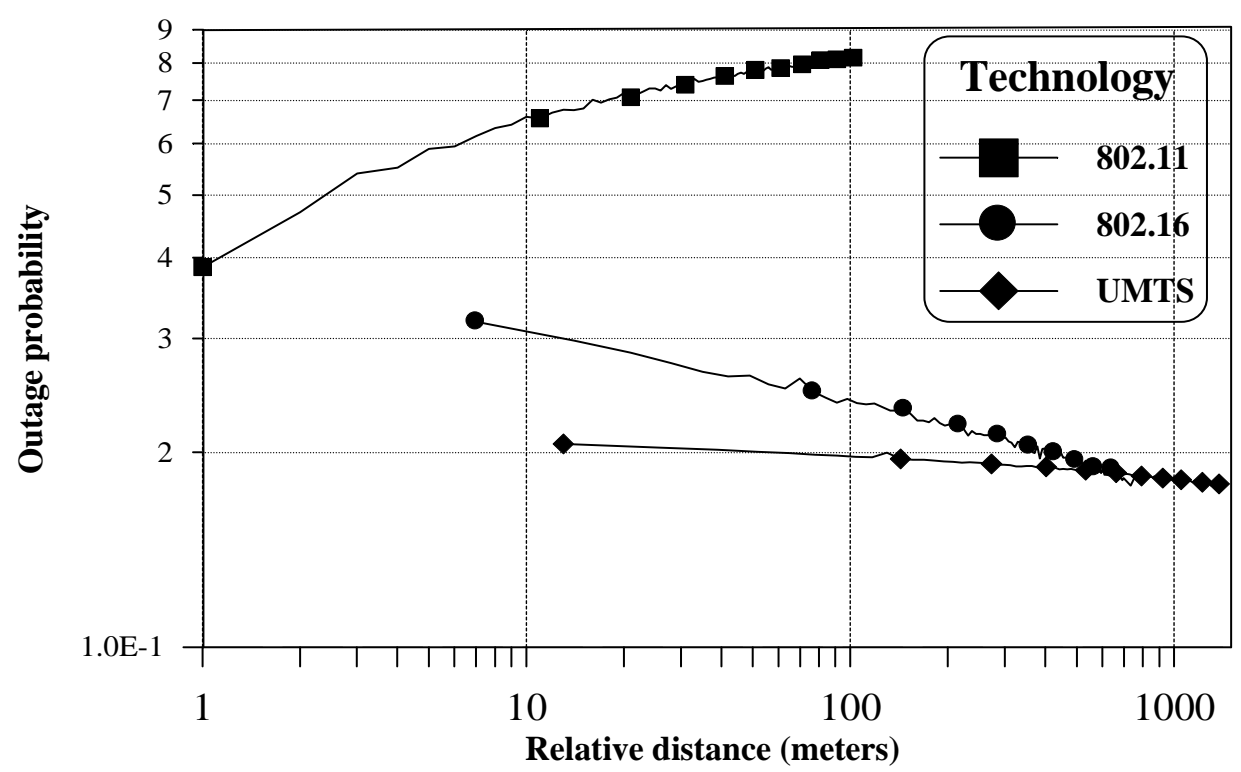

Fig.(9), Outage probability monitoring at handoff time.

\subsection{Network Scoring}

In VHO, we are faced with multiple QoS-criteria (e.g.,SINR Monj, $_{\text {out? }} \mathrm{C}_{\mathrm{rsd}}$ in our case, in addition to network access costs) during handover decision making, we can no longer easily rank the candidate networks according to our preference on a single criterion. In such cases, different criteria have to be combined and scaled in a meaningful way. In addition, various criteria in the decision process may oppose to each other. For example, when the desirable QoS increases, it may require undesirable increase in the price. Thus, trade-offs are sometimes required. The following is a working example based on the results we have presented so far:

\section{Example:}

Suppose a user has to make decision among three candidate networks: 802.11, 802.16 and UMTS. The decision problem can be expressed in the decision matrix D (Table 1.A), where the predicted measurements of each candidate networks are 
presented: $\mathrm{P}_{\text {out }}, C_{\text {rsa }}, S I N R_{\text {Moni }}$, and Cost respectively. Moreover, suppose the user has two running applications: Voice and Data. The preference (weight) on handover criteria is modeled as weights assigned by the user, as shown in Table (1.B). Now, all elements in the decision matrix, D, must be in a comparable scale. That is, if the QoS criterion is benefit, i.e. the larger, the better, the comparable scale is obtained using the weighting rule given by Equ.(17), and, clearly, Equ. (18), is applicable for cost criteria. The weighed matrix is obtained using equations (17), (16), is given by Table (1.C).

Table (1.A): Decision matrix

\begin{tabular}{|c||c|c|c|c|}
\hline \multirow{2}{*}{$\begin{array}{c}\text { Network } \\
\text { Technology }\end{array}$} & \multicolumn{4}{|c|}{ D: Decision Matrix: Monitored/Predicted Network Parameters } \\
\cline { 2 - 5 } & Pout $_{\text {out }}$ & $C_{\text {rsd }}$ & SINR $_{\text {Moni }}$ & Cost \\
\hline 802.11 & $6.527380 \mathrm{E}-01$ & $8.795717 \mathrm{E}-01$ & 29.196250 & 6.000000 \\
\hline 802.16 & $2.409183 \mathrm{E}-01$ & $3.886717 \mathrm{E}-01$ & 14.336600 & 8.000000 \\
\hline UMTS & $1.958555 \mathrm{E}-01$ & $1.313916 \mathrm{E}-01$ & 3.338140 & 10.000000 \\
\hline
\end{tabular}

$$
\begin{array}{lll}
\mathrm{y}_{\mathrm{j} j}=\mathrm{x}_{\mathrm{j} j} / \mathrm{x}_{\mathrm{i}}^{\max } & \forall \mathbf{i}_{i}, & \text { for beneficial criteria } \\
\mathrm{y}_{\mathrm{j} j}=\mathrm{x}_{\mathrm{j}}^{\min } / \mathrm{x}_{\mathrm{jj}} & \forall \mathrm{i}_{s} \mathrm{j}_{,} & \text {for cost criteria }
\end{array}
$$

\begin{tabular}{|c|c|c|c|c|}
\hline \multirow[b]{2}{*}{ Service } & \multicolumn{4}{|c|}{ P: Normalized User/Application Preferences } \\
\hline & $\mathrm{P}_{\text {out }}$ & $G_{\text {rgd }}$ & SINR Moni $_{\text {M }}$ & 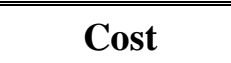 \\
\hline Voice & $4.092000 \mathrm{E}-01$ & $2.270000 \mathrm{E}-01$ & 3.182000E-01 & $4.550000 \mathrm{E}-02$ \\
\hline Data & $4.550000 \mathrm{E}-02$ & $2.270000 \mathrm{E}-01$ & $3.182000 \mathrm{E}-01$ & $4.092000 \mathrm{E}-01$ \\
\hline
\end{tabular}

Table (1.B): User preference

Table (1.C): Scaled matrix

\begin{tabular}{|c||c|c|c|c|}
\hline \multirow{2}{*}{$\begin{array}{c}\text { Network } \\
\text { Technology }\end{array}$} & \multicolumn{3}{c|}{ DS: Scaled Matrix: Monitored/Predicted Network Parameters } \\
\cline { 2 - 5 } & $\mathrm{P}_{\text {out }}$ & $C_{\text {rsd }}$ & $S_{\text {SIN }}$ & Cost \\
\hline 802.11 & $3.000523 \mathrm{E}-01$ & 1.000000 & 1.000000 & 1.000000 \\
\hline 802.16 & $8.129541 \mathrm{E}-01$ & $3.886717 \mathrm{E}-01$ & 14.336600 & $7.500000 \mathrm{E}-01$ \\
\hline UMTS & $1.493813 \mathrm{E}-01$ & $1.313916 \mathrm{E}-01$ & 3.338140 & $6.000000 \mathrm{E}-01$ \\
\hline
\end{tabular}

Now, the weighted average values of network scores with respect to voice and data applications can be obtained as follows:

\section{Network score $=\mathrm{DS} * P^{T}$}

where $\mathrm{T}$ signifies transpose. The results are given by table (1.D) below. As can be seen (table 1.D), with such a simple, straight forward network scoring procedures, the Wi Fi is having the highest score for both voice and data applications. In the next example, Table (2), we repeat the network scoring but for measurements taken at a distance of about 80 meter from the AP, with the same user preferences. 
Table (1.D): Network scores

\begin{tabular}{|c||c|c|}
\hline \multirow{2}{*}{$\begin{array}{c}\text { Network } \\
\text { Technology }\end{array}$} & \multicolumn{2}{|c|}{ Network Scores } \\
\cline { 2 - 3 } & Voice Application & Data Application \\
\hline 802.11 & $7.134814 \mathrm{E}-01$ & $9.680524 \mathrm{E}-01$ \\
\hline 802.16 & $6.233439 \mathrm{E}-01$ & $6.004476 \mathrm{E}-01$ \\
\hline UMTS & $5.067908 \mathrm{E}-01$ & $3.613108 \mathrm{E}-01$ \\
\hline
\end{tabular}

Table (2.A): Decision matrix

\begin{tabular}{|c||c|c|c|c|}
\hline \multirow{2}{*}{$\begin{array}{c}\text { Network } \\
\text { Technology }\end{array}$} & \multicolumn{4}{|c|}{ D: Decision Matrix: Monitored/Predicted Network Parameters } \\
\cline { 2 - 5 } & P $_{\text {out }}$ & $C_{\text {rsd }}$ & SINR $_{\text {Moni }}$ & Cost \\
\hline 802.11 & $7.807536 \mathrm{E}-01$ & 2.827938 & 8.335805 & 6.000000 \\
\hline 802.16 & $2.004737 \mathrm{E}-01$ & 3.801629 & 22.529620 & 8.000000 \\
\hline UMTS & $1.860872 \mathrm{E}-01$ & 7.452947 & 5.603825 & 10.000000 \\
\hline
\end{tabular}

Table (2.B): User preference

\begin{tabular}{|c||c|c|c|c|}
\hline \multirow{2}{*}{ Service } & \multicolumn{4}{|c|}{ P: Normalized User/Application Preferences } \\
\cline { 2 - 5 } & Pout $_{\text {out }}$ & $C_{r s d}$ & $S I N R_{M o n i}$ & Cost \\
\hline \hline Voice & $4.092000 \mathrm{E}-01$ & $2.270000 \mathrm{E}-01$ & $3.182000 \mathrm{E}-01$ & $4.550000 \mathrm{E}-02$ \\
\hline Data & $4.550000 \mathrm{E}-02$ & $2.270000 \mathrm{E}-01$ & $3.182000 \mathrm{E}-01$ & $4.092000 \mathrm{E}-01$ \\
\hline
\end{tabular}

Table (2.C): Scaled matrix

\begin{tabular}{|c|c|c|c|c|}
\hline \multirow{2}{*}{$\begin{array}{c}\text { Network } \\
\text { Technology }\end{array}$} & \multicolumn{4}{|c|}{ D: Scaled Matrix: Monitored/Predicted Network Parameters } \\
\hline & $P_{\text {out }}$ & $C_{\text {rsd }}$ & $S I N R_{\text {Mani }}$ & Cost \\
\hline 802.11 & $2.383430 \mathrm{E}-01$ & $3.794389 \mathrm{E}-01$ & 3.69993E-01 & 1.000000 \\
\hline 802.16 & $9.282390 \mathrm{E}-01$ & $5.100840 \mathrm{E}-01$ & 1.000000 & $7.500000 \mathrm{E}-01$ \\
\hline UMTS & 1.000000 & 1.000000 & $2.487314 \mathrm{E}-01$ & $6.000000 \mathrm{E}-01$ \\
\hline
\end{tabular}

Table (2.D): Network scores

\begin{tabular}{|c|c|c|}
\hline \multirow{2}{*}{$\begin{array}{c}\text { Network } \\
\text { Technology }\end{array}$} & \multicolumn{2}{|c|}{ Network Scores } \\
\cline { 2 - 3 } & Voice Application & Data Application \\
\hline 802.11 & $3.468944 \mathrm{E}-01$ & $6.239091 \mathrm{E}-01$ \\
\hline 802.16 & $8.479494 \mathrm{E}-01$ & $7.831240 \mathrm{E}-01$ \\
\hline UMTS & $7.426463 \mathrm{E}-01$ & $5.791664 \mathrm{E}-01$ \\
\hline
\end{tabular}

As can be seen, Table (2.D), in this case, the network scoring scheme indicates that the user should migrates to the Wi MAX network alternative but at due time as explained in Fig. (5). 


\section{SUMMARY AND CONCLUSIONS}

In this paper, vertical handoff procedure in location and speed -aware (via estimation) in heterogeneous wireless access network is being proposed. A muticriteria vertical handoff algorithm sensitive to various mobility and QoS parameters is analytically formulated and examined via simulations. It is targeted to estimate and predict the handoff metrics including outage probability, residual capacity, signal to interference and noise ratio threshold as well as network access cost. In order to avoid the ping-pong effect, a signal evolution prediction system is formulated and its performance is examined. The handoff scheme is triggered using an on line handoffinitiation-time estimation model. The handoff procedures begin with network scoring process based on multi-attributes strategy which results in selection of the most potential network. Simulation results are shown to track well the analytical formulations.

\section{APPENDEX}

Consider a time sequence $\mathrm{X}^{0}$ that denotes the raw of positive data measurements, [42],

$$
\mathrm{X}^{0}=\left(\mathrm{X}^{0}(1), \mathrm{X}^{0}(2), \ldots, \mathrm{X}^{0}(\mathrm{n})\right), \quad \mathrm{n} \geq 4
$$

the following, accumulating sequence, $\mathrm{X}^{(1)}$, is obtained:

$$
\mathrm{X}^{(1)}=\left(\mathrm{X}^{(1)}(1), \mathrm{X}^{(1)}(2), \ldots \mathrm{X}^{(1)}(\mathrm{n})\right), \quad \mathrm{n} \geq 4
$$

where,

$$
\mathrm{X}^{(1)}(\mathrm{k})=\sum_{\mathrm{i}=1}^{\mathrm{k}} \mathrm{x}^{0}(\mathrm{i}), \quad \mathrm{k}=1,2,3 \ldots \mathrm{n}
$$

and, the mean sequence, $Z_{j}^{1}$ is generated,

$$
Z^{1}=\left(Z^{1}(1), Z^{1}(2), Z^{1}(3), \ldots, Z^{1}(n)\right)
$$

where $Z^{1}(\mathrm{~K})$ is the mean sequence such that,

$$
\mathrm{Z}^{1}(\mathrm{n})=0.5\left(\mathrm{X}^{(1)}(\mathrm{k})+\mathrm{X}^{(1)}(\mathrm{k}-1)\right) \quad \mathrm{k}=1,2,3 \ldots \mathrm{n}
$$

Then, the least square estimate sequence of the grey difference equation, $G(t)$, is defined,

$G(t)=\frac{d X^{1}(t)}{d t}+a X^{1}(t)=b$

where, in the above, $[\mathrm{a}, \mathrm{b}]^{\mathrm{T}}$ is a sequence of parameters that can be found as follows:

$$
[\mathrm{a} \quad \mathrm{b}]^{\mathrm{T}}=\left(\mathrm{B}^{\mathrm{T}} \mathrm{B}\right)^{-1} \mathrm{~B}^{\mathrm{T}} \mathrm{Y} \text {, }
$$

where

$$
\mathrm{Y}=\left[\mathrm{X}^{0}(1), \mathrm{X}^{0}(2), \ldots, \mathrm{X}^{0}(\mathrm{n})\right]^{\mathrm{T}} \text { and }
$$




$$
\mathrm{B}=\left[\begin{array}{ccc}
-\mathrm{Z}^{1}(2) & 1 \\
-\mathrm{Z}^{1}(3) & 1 \\
= & \\
\cdot & \\
\cdot & \\
-\mathrm{Z}^{1}(\mathrm{n}) & 1
\end{array}\right]
$$

The solution of Equ. (A. 6) at time $\mathrm{K}$ is, therefore, given by,

$\mathrm{X}_{\mathrm{p}}^{0}(\mathrm{k}+1)=\left(\mathrm{X}^{0}(1)-\frac{\mathrm{b}}{\mathrm{a}}\right) \mathrm{e}^{-\mathrm{ak}}\left(1-\mathrm{e}^{\mathrm{a}}\right)$

and the predicted value of data at a future time $(\mathrm{k}+\mathrm{H})$ is,

$X_{p}^{0}(k+H)=\left(X^{0}(1)-\frac{b}{a}\right) e^{-a(k+H-1)}\left(1-e^{a}\right)$

\section{REFERENCES}

[1] A. Benmimoune and M. Kadoch, "Vertical handoff between UMTS and WLAN", in Proceedings of the 4th international conference on Communications and information technology (CIT’10), pp., 131-140, Corfu Island, Greece, 2010.

[2] K. Ahmavaara, H. Haverinen, and R. Pichna, "Interworking Architecture between 3 GPP and WLAN Systems", IEEE Communications Magazine, vol. 41, no 11, pp.74 -81, December 2006.

[3] M. Lott, M. Siebert, S. Bonjour, D. von Hugo, "Interworking of WLAN and 3G systems", IEEE Communications magazine, vol. 151, pp.34-41, no.5, May 2006.

[4] D. Han, D. Andersen, M. Kaminsky, K. Papagiannaki, and S. Seshan, "Access point localization using local signal strength gradient", in Passive and Active Network Measurement, volume 5448, chapter 10, pages 99-108. Springer Berlin Heidelberg, Berlin, Heidelberg, 2009.

[5] N. Nasser, A. Hasswa, and H. Hassanein, "Handoffs in Fourth Generation Heterogeneous Networks", IEEE Communications Magazine, vol. 44, no.10, pp. 96-103, October 2006.

[6] Richard Rouil, Nada Golmie, Nicolas Montavont "Media Independent Handover Transport using Cross-layer optimized SCTP", Elsevier, Computer Communication, 2010.

[7] P.Khadivi, T.D.Todd, S.Samavi, H.Saidi and D.Zhao, "Mobile Ad Hoc Relaying in Hybrid WLAN/Cellular Systems for Dropping Probability Reduction", Proceedings of the 9th CDMA International Conference (CIC 2006), Korea, pp.25-28, March 2006.

[8] J. McNair and F. Zhu, "Vertical Handoffs in Fourth-generation Multinetwork Environments," IEEE Wireless Comm., vol. 11, no. 3, June 2004.

[9] "Draft IEEE Standard for Local and Metropolitan Area Networks: Media independent Handover Services, ” IEEE, P802.21/D00.01, July 2005.

[10] S. Lee, K. Sriram, K. Kim, Y. H. Kim, and N. Golmie, "Vertical handoff decision algorithms for providing optimized performance in heterogeneous wireless networks', IEEE Transactions on Vehicular Technology, 58(2):865-881, 2009 
[11] Sudipta Patowary, Nityananda Sarma and Siddhartha Sankar Satapathy "SINR based Vertical Handoff Algorithm between GPRS and Wi-Fi Networks," Special Issue of IJCCT Vol.1, Issue 2, 3, 4; 2010 for International Conference ACCTA2010, 3-5, August, 2010

[12] "Draft IEEE Standard for Local and Metropolitan Area Networks: Media Independant Handover Services, IEEE P802.21/D02.00," September 2006, http://www .ieee802.org/21/.

[13] C. E. Perkins, "Mobile IP," IEEE Communications Magazine, vol. 40, no. 5, pp. 66-82, 2002.

[14] "3GPP System toWireless Local AreaNetwork (WLAN) Interworking; System Description (Release 7), 3GPP TS 23.234 V7.5.0,” March 2007, http://www.3gpp.org/.

[15] H. Wang, R. Katz, and J. Giese, "Policy-enabled handoffs across heterogeneous wireless networks," in Proceedings of the 2nd IEEE Workshop on Mobile Computing Systems and Applications (WMCSA '99), pp. 51-60, New Orleans, LA, USA, February 1999.

[16] F. Zhu and J. McNair, "Multiservice vertical handoff decision algorithms," EURASIP Journal on Wireless Communications and Networking, vol. 2006, Article ID 25861, 13 pages, 2006.

[17] T. Ahmed, K. Kyamakya, and M. Ludwig, "A context-aware vertical handover decision algorithm for multimode mobile terminals and its performance," in Proceedings of IEEE/ACM Euro American Conference on Telematics and Information Systems (EATIS '06), pp. 19-28, Santa Marta, Colombia, February 2006.

[18] A. Hasswa, N. Nasser, and H. Hassanein, "Tramcar: a context aware cross-layer architecture for next generation heterogeneous wireless networks," in Proceedings of IEEE International Conference on Communications (ICC '06), vol. 1, pp. 240245, Istanbul, Turkey, June 2006.

[19] S. Balasubramaniam and J. Indulska, "Vertical handover supporting pervasive computing in future wireless networks," Computer Communications, vol. 27, no. 8, pp. 708-719, 2004.

[20] T. L. Saaty, "How to make a decision: the analytic hierarchy process," European Journal of Operational Research, vol. 48, no. 1, pp. 9-26, 1990.

[21] P. M. L. Chan, R. E. Sheriff, Y. F. Hu, P. Conforto, and C. Tocci, "Mobility management incorporating fuzzy logic for a heterogeneous IP environment," IEEE Communications Magazine, vol. 39, no. 12, pp. 42-51, 2001.

[22] P. Chan, Y. Hu, and R. Sheriff, "Implementation of fuzzy multiple objective decision making algorithm in a heterogeneous mobile environment," in Proceedings of IEEE Wireless Communications and Networking Conference (WCNC '02), vol. 1, pp. 332-336, Orlando, Fla, USA, March 2002.

[23] M. Chiu and M. Bassiouni, "Predictive schemes for handoff prioritisation in cellular networks based on mobile positioning," IEEE Journal on, Selected Areas in Communications, vol. 18, pp. 510 U522, March 2000.

[24] G. Pollini, "Trends in handover design," Communications Magazine, IEEE, vol. 34, no. 3, pp. 82-90, 1996. 
[25] K. Taniuchi, Y. Ohba, V. Fajardo, S. Das, M. Tauil, Y.-H. Cheng, A. Dutta, D. Baker, M. Yajnik, and D. Famolari, IEEE 802.21: "Media independent handover Features, applicability, and realization", IEEE Communications Magazine, 47(1), pp. 112-120, 2009.

[26] M. Liu, Z. Li, X. Guo, and E. Dutkiewicz, "Performance Analysis and Optimization of Handoff Algorithms in Heterogeneous Wireless Networks," IEEE Transaction on Mobile Computing, vol. 7, no. 7, pp. 846-857, 2008.

[27] K. Yang, I. Gondal, B. Qiu and L. S. Dooley, "Combined SINR Based Vertical Handoff Algorithm for Next Generation Heterogeneous Wireless Networks," IEEE GLOBECOM, pp. 4483-4487, 2007.

[28] Xiaohuan Y, Y.Ahmet S, Sathya N, "A survey of vertical handover decision algorithms in fourth generation heterogeneous wireless networks", The International Journal of Computer and Telecommunications Networking; Vo. 54, No. 11, pp. 1848-1863, August, 2010.

[29] Peng Xu; Xuming Fang, Jun Yang, Yaping Cui, "A User's State and SINR Based Handoff Algorithm in Hierarchical Cell Networks", IEEE Wireless Communications Networking and Mobile Computing (WiCOM), pp. 1-4, Sept. 23-25, 2010.

[30] Pahlavan, P. Krishnamurthy, A. Hatami, M. Ylianttila, J. Makela, R. Pichna and J.Vallstom, "Handoff in Hybrid Mobile Data Networks", IEEE Personal Communications, pp.34-46, April 2006

[31] A.H.Zahran and B.Liang, "Performance Evaluation Framework for Vertical Handoff Algorithms in Heterogeneous Networks", Proceedings of the IEEE International Conference on Communications (ICC 2005), Vol.1, pp.173-178, April 2005.

[32] Taehoon Kim, Sang-wook Han, Youngnam Han, "A QoS-aware vertical handoff algorithm based on service history information," IEEE Communications Letters, Vol. 14, No. 6, pp. 527-529, June 2010.

[33] Cao, L, "Support vector machines experts for time series forecasting", Neurocomputing, 51, pp. 321-339, 2003.

[34] Deng, J, "Control problems of grey system", Systems \& Control Letters, Vol.1, pp. 288-294, 1982.

[35] Wen, K. L., \& Huang, Y. F., "The development of grey Verhulst toolbox and the analysis of population saturation state in taiwan-Fukien", In Proceedings of IEEE international conference on systems, man and cybernetics, The Netherlands, Vol. 6, pp. 5007-5012, 2004.

[36] Ahmed H.Zahram, Ben liang and Aladdin Dalch, "Signal threshold adaptation for vertical handoff on heterogeneous wireless networks", ACM/Springer Mobile Networks and Applications (MONET) journal, Vol.11, No.4, pp 625-640, August 2006.

[37] M. Ylianttila, M. Pande, J. Makela, and P. Mahonen, "Optimization Scheme for Mobile Users Performing Vertical Handoffs between IEEE 802.11 and GPRS/EDGE networks," In Proceedings of the IEEE Global Telecommunication Conference (GLOBECOM), San Antonio, TX, USA, Dec. 2001.

[38] R. Hsieh, Z. G. Zhou, and A. Senevirante, "S-MIP: A Seamless Handoff Architecture for Mobile IP," In Proceedings of IEEE INFOCOM, San Francisco, CA, USA, March 30 - April 3, 2003. 
[39] M.-H. Ye, Y. Liu, H.-M. Zhang, “The Mobile IP Handoff between Hybrid Networks," In Proceedings of the 13th IEEE International Symposium on Personal, Indoor, and Mobile Radio Communications (PIMRC), Lisbon, Portugal, pp. 1263-1276, 15 - 18 Sep. 2002.

[40] Dayal C. Sati, Pardeep Kumar, Yogesh Misra, " FPGA implementation of a fuzzy logic based handoff controller for microcellular mobile networks", International journal of applied engineering research, Vol. 1, pp. 52-62, 2011

[41] Z. N. L. Wang, Y. Zhu, H. Deng, and M. Yano, "Integration of SNR, load and time in handoff initiation for wireless LAN," Personal, Indoor and Mobile Radio Communications (PIMRC), Vol. 3, pp. 2032-2036, 2003.

[42] E. Kayacan, B. Ulutas and O Kaynak "Grey system theory-based models in time series prediction", Expert Systems with Applications 37, pp. 1784-1789, 2010: journal homepage: www.elsevier.com/locate/eswa

\section{أسلوب شامل للتنقل بين الثبكات اللاسلكية متعددة الأنواع و التكنولوجيات}

بقدم هذا البحث طريقه شامله ذات كفائه عالبه للتتقل بين شبكات التراسل اللاسلكية متعدة الأنواع والتكنولوجيات. تعتدد هذه ألطريقه على تقدير إحصائي لعدد من معاملات التراسل الاساسيه والتتي تعتدد عليها

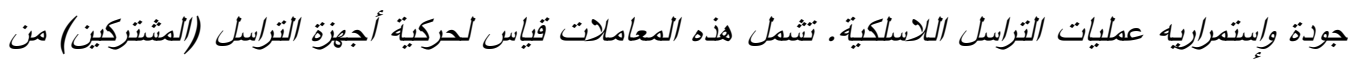
خلال ثقدبر السرعة والبعد عن مصدر الإسال. من ناحية أخرى تم وضع ندوذج تحليلي لتقدبر الوقت الأمثل لاستئناف عمليه الانتقال الفعلي من شبكه إلى أخرى بهذف ضمان إستمراريه التراسل مع الحفاظ على مستوى ألجوده المطلوبة وذلك عن طريق ندوذج مقترح لتقدبر سعه الثبكات وكذلك /حتمال خروج المشترك من مجال ألتغطبه اللاسلكبة. عدليا، عند توافر أكثر من شبكه لتغطبة التراسل بيكن للمشترك اختبار أنسب هذه الثبكات.

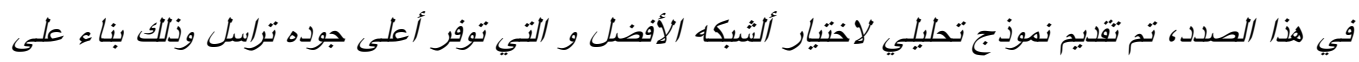

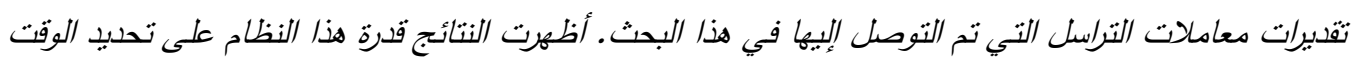
الأنسب للانتقال بين الشبكات المتعددة وكذلك اختيار أفضل الشبكات الني توفر أنسب معاملات التراسل لضمان استمرار التواصل مع الحفاظ على مستوى ألجوده المطلوبة. 